\title{
Obstrucción ureteral secundaria a enfermedad de Rosai-Dorfman
}

\author{
R. Ferrero Doria, E. Huertas Valero*, F. García Víctor, M. Gassó Matoses, F. Moreno Pérez, \\ S. Calatrava Gadea, E. Díaz Calleja
}

Servicio de Urología. *Servicio de Anatomía Patológica. Hospital Francesc Borja de Gandía. Valencia.

Actas Urol Esp 2005; 29 (2): 234-237

\section{RESUMEN \\ OBSTRUCCIÓN URETERAL SECUNDARIA A ENFERMEDAD DE ROSAI-DORFMAN}

La obstrucción ureteral puede ser secundaria a múltiples causas. Presentamos un caso poco común dentro de la práctica urológica habitual, consistente en una forma de Histiocitosis denominada Enfermedad de Rosai-Dorfman, como origen de obstrucción ureteral extrínseca. En la presente comunicación describimos la forma de presentación, la metodología diagnóstica utilizada y el tratamiento propuesto.

Palabras clave: Uréter. Estenosis ureteral. Histiocitosis. Enfermedad Rosai-Dorfman. Corticoides.

\section{ABSTRACT}

\section{URETERAL OBSTRUCTION SECONDARY TO ROSAI-DORFMAN DISEASE}

Ureteral obstruction can be secondary to a lot of reason. We present a uncommon case report of ureteral obstruction to Rosai-Dorfman disease. The form of clinic presentation is described, the diagnostic methods used and the therapeutic management.

Keywords: Ureter. Ureteral estenosis. Histiocytosis. Rosai-Dorfman disease. Corticosteroids.

$\mathrm{D}$ entro de la patología urológica habitual nos encontramos con múltiples causas de enfermedades que provocan disminución del calibre ureteral. Los urólogos las solemos clasificar en intrínsecas, cuando están localizadas en la luz ureteral y extrínsecas cuando el origen está en la periferia de éste.

Por otro lado, tenemos la Enfermedad de RosaiDorfman (ERD), que es una entidad rara, de características proliferativas, perteneciente al grupo de la Histiocitosis sinusales con linfadenopatías masivas (SLHM) y que suele manifestarse por linfadenopatías masivas, de gran tamaño y de localización preferente a nivel cervical. Se trata de una enfermedad diferenciada en 1969 y 1972 por Rosai y Dorfman ${ }^{1}$, de causa desconocida, consecuencia de una alteración del sistema inmuni$\operatorname{tario}^{2}$. No se conoce la patogenia ni tiene un tratamiento específico.

Presentamos un caso de obstrucción ureteral extrínseca debida a esta enfermedad.

\section{CASO CLINICO}

Se trata de un varón de 38 años ingresado a cargo del Servicio de Urología por clínica compatible con cólico nefrítico izquierdo complicado con ITU. Los antecedentes del paciente son: hipoplasia pulmonar congénita, dextrocardia, diagnosticado VIH positivo hacía unos meses y en tratamiento con antiretrovirales, no presentando en ese momento carga viral. Tratado con isoniacida por un Mantoux positivo. También tenía antecedentes de un cólico nefrítico izquierdo hacía unos meses.

En el primer estudio de urgencias únicamente destaca una puñopercusión renal izquierda positiva, leucocituria, nitritos positivo y formula sanguínea con desviación izquierda. En la ecografía se observa ectasia pielocalicial izquierda sin imágenes sugestivas de litiasis en la radiografía simple de aparato urinario.

La urografía intravenosa (Fig. 1) muestra ureteropielocaliectasia izquierda hasta zona de este- 


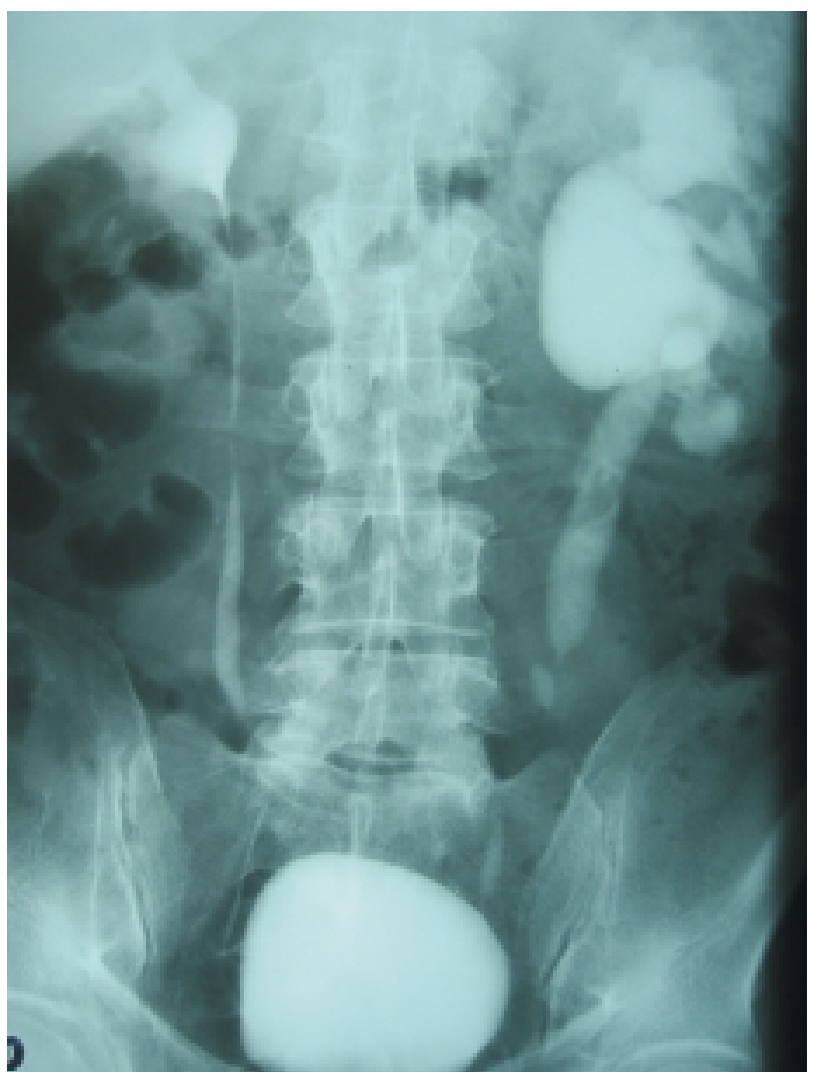

FIGURA 1. UIV: ureteropileocaliectasia izquierda por doble estenosis de uréter.

nosis doble a nivel de unión uréter medio con uréter terminal.

Pensamos en distintas alternativas como origen de las mismas, desde litiasis radiotransparente, lesión estenótica de origen tuberculoso, fungus ball, tumor transicional de uréter (la citología urinaria era negativa), lesión retroperitoneal compresiva, linfomas. Considerando poco clara la imagen urográfica, optamos por una ureteroscopia exploradora, observándose una zona de estenosis que permitió el paso del ureteroscopio con dificultad y una segunda estenosis imposible de franquear. Se colocó catéter doble "J" como derivación urinaria momentánea.

El TAC (Fig. 2) mostró masa retroperitoneal característica de las fibrosis situada sobre el músculo psoas alrededor de la encrucijada del uréter con los vasos iliacos.

Ante la imposibilidad de obtener muestra percutánea con PAAF nos inclinamos por la realización de laparotomía exploradora y ureterolisis. Durante la misma el sigma se encontraba fuertemente adherido a la masa, dificultando su

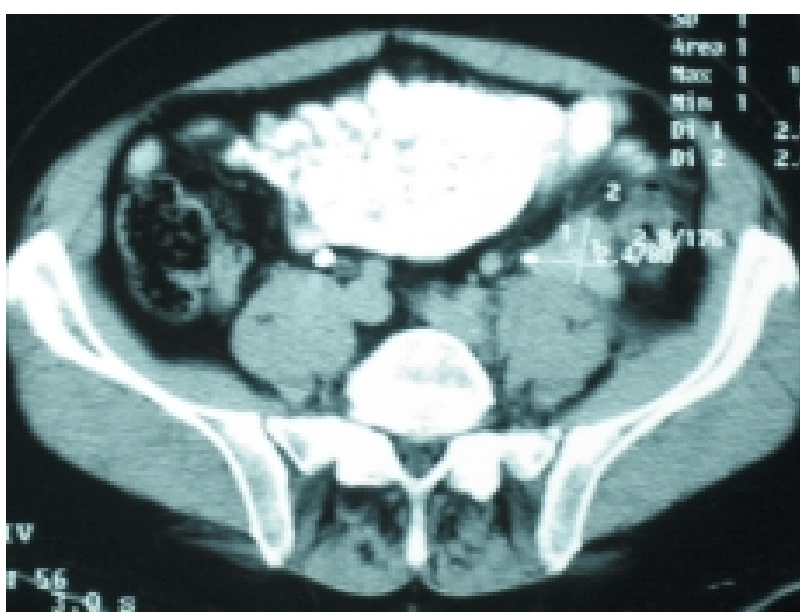

FIGURA 2. TAC abdominal: masa retroperitoneal sobre músculo psoas que engloba uréter iliaco y grandes vasos.

movilización, siendo ésta una lesión dura, pétrea, no móvil que englobaba al uréter y vasos iliacos y resultando imposible la liberación de la vía urinaria a este nivel. Se obtiene muestra para estudio patológico, se procede a recambio de catéter doble "J"y se cierra la herida quirúrgica.

El informe anatomopatológico (Fig. 3) describe tejido fibroadiposo con células histiocíticas y linfoplamocitarias. Áreas de fibrosis densa y otras más laxas donde los histiocitos se distribuyen al azar, siendo éstos de núcleo grande, redondo, vesicular, frecuente nucleolo y con atipia ocasional. El citoplasma es claro, amplio o granular, presentando emperipolesis (Linfofagocitosis). La inmunohistoquímica revela que los histiocitos son positivos para S-100 y para CD-68 y negativos para keratina MNF-116, para PAS, Gram y

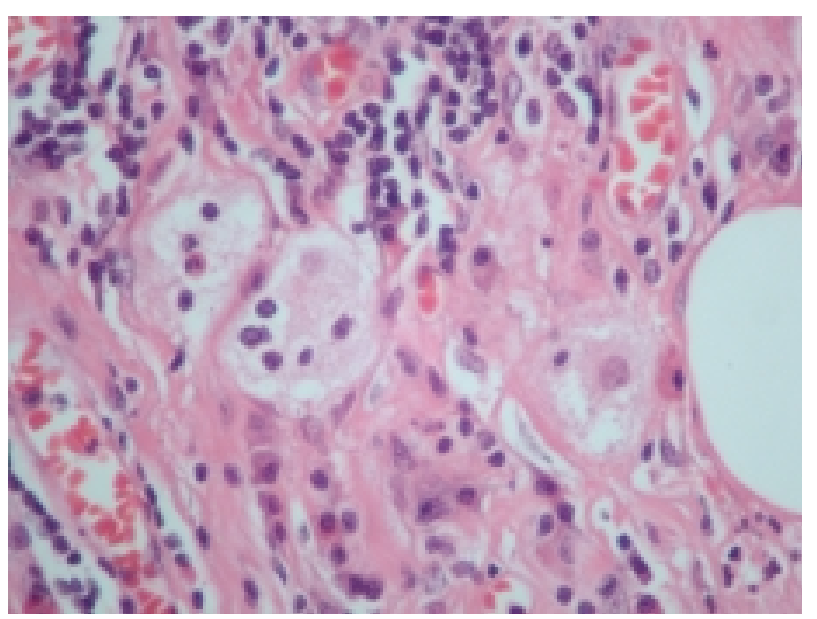

FIGURA 3. Preparación patológica: Tinción de HematoxilinaEosina. Histiocitos benignos con linfofagocitosis. 
Ziehl. Los acúmulos linfoides presentan una población mixta de linfocitos CD-3 y CD-20 positivos, siendo negativo el bcl-2 en el centro folicular. Todo ello planteaba diagnóstico diferencial con proliferaciones neoplásicas o no, como son la fibrosis retroperitoneal, pseudotumor inflamatorio o xantogranuloma retroperitoneal, así como otras de naturaleza infecciosa como por micobacterias y malacoplakia, entre otras. La emperipolesis asociada a la positividad para la S-100 en los histiocitos son datos comunes en la Enfermedad de Rosai-Dorfman.

Tras revisión de la literatura se inicia un tratamiento médico con prednisona 30 a dosis de $0,5 \mathrm{mg} / \mathrm{kg}$ de peso durante un mes, con reducciones de la dosis transcurrido este tiempo.

Tras cuatro meses de tratamiento el paciente sigue con sus retrovirales, permaneciendo asintomático y presentando en la urografía de control una desaparición de la ureteropielocaliectasia izquierda (Fig. 4).

\section{DISCUSIÓN}

La obstrucción del uréter es una patología frecuente ante la que se enfrenta el urólogo en su actividad diaria. Es mucho más frecuente que ésta sea de origen interno que externo. Cuando la estenosis es por compresión extrínseca el diagnóstico es algo más difícil y suele necesitar de gran arsenal de pruebas diagnósticas.

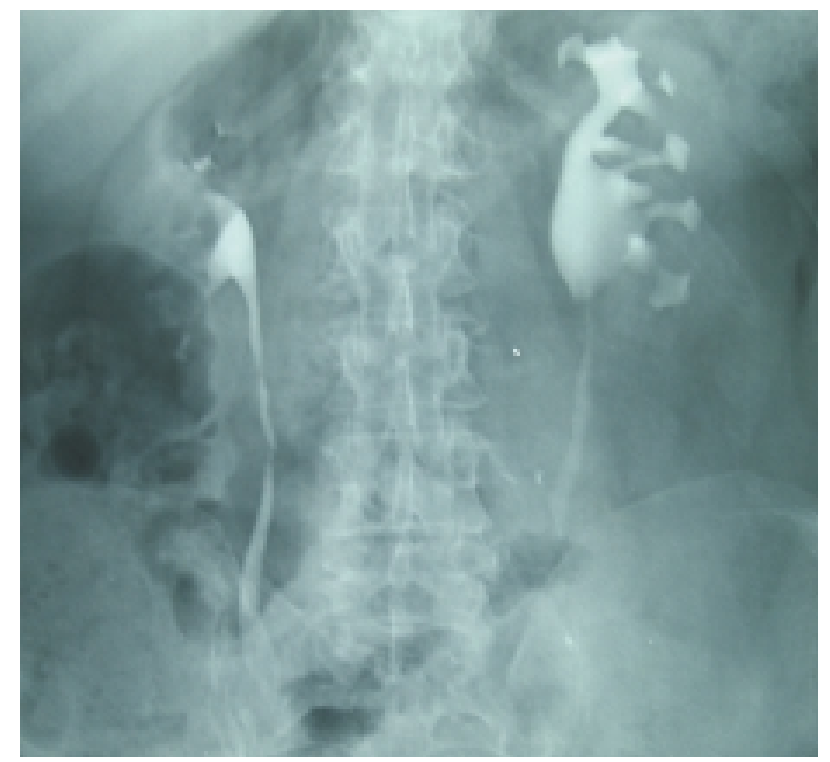

FIGURA 4. UIV a los 4 meses: Desaparición de la ectasia tras tratamiento con corticoides.
La mayor parte de los casos la obstrucción extrinseca ureteral es unilateral y crónica por lo que el manejo puede que no requiera una actuación urgente.

La Enfermedad de Rosai-Dorfman (histiocitosis sinusal con linfadenopatías masivas) es considerada por consenso como una histiocitosis idiopática $^{1,2}$. Algunos autores hipotetizan que se trate de un desorden inmunológico asociado a un antecedente infeccioso. Más frecuente en niños y en jóvenes, pero los casos de afectación exclusiva extraganglionar son más frecuentes en adultos ${ }^{3}$.

Las manifestaciones clínicas son la presencia de adenopatías cervicales bilaterales (90\%), grandes, indoloras o en cualquier otra localización ganglionar ${ }^{1-3}$. Es posible la afectación únicamente extranodal, aunque menos frecuente, por lo que su denominación más correcta no sería SLMM sino $\mathrm{ERD}^{3}$.

La afectación extraganglionar más frecuente es la piel, tracto respiratorio superior, glándulas salivares $^{1,3,4}$. También se han publicado casos con afectación retroorbitaria ${ }^{2,5}$ provocando incluso ceguera.

Se describen 5 patrones evolutivos ${ }^{4}$ :

1. Remisión completa y espontánea (50\%),

2. Curso crónico con exacerbaciones y remisiones,

3. Enfermedad persistente y estable,

4. Enfermedad progresiva y

5. Diseminación nodal y extranodal con evolución fatal (7\%).

Evidentemente el diagnóstico de la lesión se establece tras el estudio anatomopatológico, definido por la presencia de histiocitos positivos, por inmunohistoquimia, a la proteína S-100 y presencia casi constante de un fenómeno denominado emperipolesis (linfofagocitosis) ${ }^{1,6,7}$. En la afectación extranodal el patrón histológico es semejante pero con mayor fibrosis y menor cantidad de histiocitos ${ }^{3,6}$, y presencia más frecuente de emperipolesis ${ }^{6}$.

$\mathrm{El}$ diagnóstico diferencial anatomopatológico en la afectación extranodal se realiza con enfermedad de Hodgkin, linfoma no Hodgkin, carcinoma metastásico y melanoma maligno metastásico ${ }^{1,3,6}$.

La Enfermedad de Rosai-Dorfman no tiene tratamiento etiológico, recurriéndose a la cirugía como tratamiento sintomático en casos necesa- 
$\operatorname{rios}^{1-4,6}$. Se ha probado con radioterapia y quimioterapia $\sin$ observarse efectividad ${ }^{3,6,2}$. También se ha utilizado el metotrexate y la 6-mercamptopurina ${ }^{8}$, así como corticoides ${ }^{4}$.

Nuestro caso representa una Enfermedad de Rosai-Dorfman con afectación extranodal en el entorno de un paciente VIH positivo, de localización retroperitoneal, que causaba una obstrucción extrínseca ureteral con la consecuente dilatación de la vía excretora y que tras tratamiento con corticoides se objetivó una normalización de la ureteropielocaliectasia.

\section{REFERENCIAS}

1. Foucar E, Rosai J, Dorfman R. Sinus Histiocitosys with Massive Lymphadenopathy (Rosai-Dorfman Disease): Review of the Entity. Seminars in Diagnostic Pathology 1990;7(1): 1973.

2. Remadi S, Doussis AnagnostopouloI, Jlidi R, Cox JN, Seemayer TA. Extranodal Rosai-Drfman Disease in Childhood. Path Res Pract 1996;192:1007-1015.

3. Carbone A, Passannante A, Gloghini A, Devaney K, Rinaldo A, Ferlito A. Review of Sinus Histiocytosis with massive Lymphadenopathy (Rosai-Dorfman Disease) of head and neck. Ann Otol Rhinol Laryngol 1999;108:1095-1104.
4. A. Ferrer Rodriguez et al. " Enfermedad de Rosai-Dorfman (Histiocitosis Sinusal con Linfadenopatías masivas): a propósito de un caso”. Acta Otorrinolaringol Esp 2003;54:384387.

5. Khan R, MoriartY P, Kennedy S. "Rosai Dorfman disease or sinus histiocytosis with massive lymphadenopathy of the orbit”. Br J Ophthalmol. 2003 Aug;87 (8):1054.

6. Wenig B, Abbondanzo S, Childers E, Kapadia S, Heffner R. Extranodal Sinus Histiocitosys with Massive Lymphadenopathy (Rosai-Dorfman Disease) of the Head and Neck. Human Pathology 1993;24(5):483-492.

7. Álvarez Alegret R, Martínez Tello A, Ramírez T, Gallego P, Marinez D, García Julián. Sinus Histiocitosys with Massive Lymphadenopathy (Rosai-Dorfman Disease): diagnosis with fine-needle aspiration in case with nodal and nasal invoilvent. Diagn Cytopathol 1995;13(4):333335.

8. Horneff G, Jurgens H, Hort W, Karitzky D, Gobel U. Sinus Histiocitosys with Massive Lymphadenopathy (RosaiDorfman Disease): response to methotrexate and mercatopurine. Med Pediatr Oncol 1996;27(3):187-192.

Dr. R. Ferrero Doria

Avda. Albaida nํㄹ, escalera 1, pta. 18.

46870 Ontinyent (Valencia)

(Trabajo recibido el 16 abril de 2004) 